\title{
Discussion of "Quantifying the Impacts of Climate Change and Human Activities on Runoff Variation: Case Study of the Upstream of Minjiang River, China” by Shuqi Liang, Wensheng Wang, Dan Zhang, Yueqing Li, and Guoqing Wang \\ DOI: 10.1061/(ASCE)HE.1943-5584.0001980
}

\author{
Mahsa Jahandideh-Tehrani ${ }^{\mathrm{a}}$ \\ ${ }^{\text {a }}$ School of Engineering and Built Environment, Gold Coast Campus, Griffith University, Gold Coast, QLD, \\ 4222, Australia
}

The discusser would like to thank the valuable work of the original paper on quantifying the impacts of climate change and human activities on runoff variations. Many studies have analyzed the impacts of climate change or human activities in the upstream of Minjiang River (UMR), China. Yet, simultaneous consideration of impacts of changes in precipitation and temperature (climate change factors), and human activities on runoff variations in the UMR had not been previously investigated, as studied in the original paper.

In the discussed study, the double mass curve method and the modified method of slope change ratio of accumulative quantity (modified SCRAQ) have been applied to separately estimate the contributions of climate change (precipitation and temperature) and human activities on runoff variations in the UMR over 1960-2012. Additionally, the Mann-Kendall test has been applied to detect the trends and the abrupt change of hydro-meteorological time series.

Although the work under discussion introduced and applied three efficient methods for analyzing runoff variations as a result of climate change and human activities, the discusser would like to draw authors' attention to the following points, which can help the authors of the original paper and other researchers in future studies on hydrological trend analysis: 
- Mann-Kendall test, which is a nonparametric method for trend detection in different hydrologic and climatologic time series (Dinpashoh et al., 2014), has been applied in the discussed paper. This test does not require the data to be normally distributed or to follow any particular statistical distributions (Lacombe et al., 2012; Sa'adi et al., 2019). However, the important requirement of the Mann-Kendall test is that the data to be independent. Therefore, any positive and negative auto-correlation of the data should be eliminated before applying the MannKendall test (Lacombe et al., 2012; Sa'adi et al., 2019). Prior to trend analysis, such autocorrelation impact should be eliminated by (i) applying "pre-whitening" methods (removing serial correlation in hydro-meteorological time series) or (ii) modifying the original MannKendall test (trend-free pre-whitening) (Sa'adi et al., 2019). The data independency has not been checked and eliminated (if applicable) in the original paper.

- Furthermore, the Mann-Kendall test has been applied for trend analysis over a 53-year period (1960-2012) in the discussed paper, whereas recent analysis of hydro-meteorological multicentennial time series indicated that wet or dry periods can exceed 50 years (Shahid et al., 2014; Sa'adi et al., 2019). It has been also revealed that the long-term persistence (LTP) or Hurst phenomenon can affect the trend analysis (Shahid et al., 2014). As a result, scaling behavior should be accounted when applying the Mann-Kendall test to ensure the ability of the test in discriminating multi-scale variability from unidirectional trends (Hamed, 2008). Therefore, in case of limited availability of long-term data, the scaling behavior should be considered by authors of the original paper when using the Mann-Kendall test.

\section{References}

Dinpashoh, Y., Mirabbasi, R., Jhajharia, D., and Zare Abianeh, H. 2014. "Effect of short-term and long-term persistence on identification of temporal trends." J. Hydrol. Eng., 19 (3). DOI: https://doi.org/10.1061/(ASCE)HE.1943-5584.0000819 
Hamed, K. H. 2008. "Trend detection in hydrologic data: The Mann-Kendall trend test under the scaling hypothesis." J. Hydrol., 349 (3-4), 350-363. DOI: https://doi.org/10.1016/j.jhydrol.2007.11.009

Lacombe, G., McCartney, M., and Forkuor, G. 2012. "Drying climate in Ghana over the period 19602005: evidence from the resampling-based Mann-Kendall test at local and regional levels." Hydrolog. Sci. J., 57 (8), 1594-1609. DOI: https://doi.org/10.1080/02626667.2012.728291

Sa'adi, Z., Shahid, S., Ismail, T., Chung, E. S., and Wang, X. J. 2019. “Trends analysis of rainfall and rainfall extremes in Sarawak, Malaysia using modified Mann-Kendall test." Meteorol. Atmos. Phys., 131, 263-277. DOI: https://doi.org/10.1007/s00703-017-0564-3.

Shahid, S., Wang, X. J., and Harun, S. B. 2014. "Unidirectional trends in rainfall and temperature of Bangladesh.” In Hydrology in a Changing World, Proc. The FRIEDN-Water, 363 (6), 177-182. IAHS Press: Montpellier, France. 